\title{
One-Pot Synthesis of Monodisperse Colloidal Copper-Doped CdSe Nanocrystals Mediated by Ligand-Copper Interactions
}

\author{
Luming Yang, Kathryn E. Knowles, Atchuthan Gopalan, Kira E. Hughes, Michael C. James, \\ and Daniel R. Gamelin* \\ Department of Chemistry, University of Washington, Seattle, WA 98195-1700
}

Email: gamelin@chem.washington.edu

\section{EXPERIMENTAL METHODS}

Chemicals. Oleic acid (90\%), Copper Iodide (CuI, 98\%), Octadecene (ODE, 90\%), Selenium dioxide $\left(\mathrm{SeO}_{2}, 99.9+\%\right)$, Oleylamine (OAm, 70\%), Dioctylamine $(90 \%)$, Trioctylamine (98\%), Dodecanethiol (DDT, > 98\%), and Cadmium acetate hydrate $\left(\left(\mathrm{CH}_{3} \mathrm{CO}_{2}\right)_{2} \cdot \mathrm{xH}_{2} \mathrm{O}, 98 \%\right)$ were purchased from Sigma-Aldrich and used without further purification. Sodium hydroxide $(\mathrm{NaOH}, 95.0 \%$ - 100.5\%) and Toluene $(99.9 \%)$ were purchased from Fisher and used without further purification. Cadmium nitrate tetrahydrate $\left(\mathrm{Cd}\left(\mathrm{NO}_{3}\right)_{2} \cdot 4 \mathrm{H}_{2} \mathrm{O}, 98 \%\right.$ ), and Trioctylphosphine (TOP, $>97 \%$ ) were purchased from STREM Chemicals and used without further purification.

Synthesis of $\mathrm{Cu}^{+}: \mathrm{CdSe}$ Nanocrystals with $\mathrm{Cu}_{2-\mathrm{x}} \mathrm{Se}$ Nanocrystals as the Copper Precursor. $0.135 \mathrm{~g}$ cadmium oleate, $0.022 \mathrm{~g}$ selenium dioxide, $0.015 \mathrm{mM} \mathrm{Cu}_{2-\mathrm{x}} \mathrm{Se} \mathrm{NCs}$, $10.00 \mathrm{~g}$ ODE are degassed under vacuum at $55^{\circ} \mathrm{C}$ for $45 \mathrm{~min}$ and heated to $235{ }^{\circ} \mathrm{C}$ under nitrogen atmosphere. Aliquots are removed from the reaction and the product is isolated following the standard synthesis. $\mathrm{Cu}_{2-\mathrm{x}} \mathrm{Se} \mathrm{NCs}$ are synthesized following a previously reported procedure. ${ }^{1}$

Synthesis of $\mathrm{Cu}^{+}$:CdSe Nanocrystals with Purified CdSe Nanocrystals. $0.135 \mathrm{~g}$ cadmium oleate, $0.022 \mathrm{~g}$ selenium dioxide, $10.00 \mathrm{~g}$ ODE are degased under vacuum at $55^{\circ} \mathrm{C}$ for $45 \mathrm{~min}$ and heated to $235^{\circ} \mathrm{C}$ under nitrogen atmosphere following the standard method as is described in the Experimental Method section in the main text. After reacting at $235^{\circ} \mathrm{C}$ for $5 \mathrm{~min}$, half of the reaction mixture is removed and purified following the standard procedure. These undoped CdSe NCs are then resuspended in ODE, and are degassed under vacuum at $55{ }^{\circ} \mathrm{C}$ for $45 \mathrm{~min}$ and heated to $235^{\circ} \mathrm{C}$ under nitrogen atmosphere. A copper precursor containing $34.6 \mathrm{mg} \mathrm{CuI}$ and $2.4 \mathrm{~g}$ ODE is made following the standard synthesis and is injected into the CdSe solution after heating at $235{ }^{\circ} \mathrm{C}$ for $5 \mathrm{~min}$. The reaction mixture is cooled to room temperature and the NCs are purified following the standard procedure. For the other half of the original reaction mixture, same amount of copper precursor is injected after reacting at $235^{\circ} \mathrm{C}$ for $5 \mathrm{~min}$. It is cooled down to room temperature after reacting at 235 ${ }^{\circ} \mathrm{C}$ for $20 \mathrm{~min}$ and the NCs are purified following the standard procedure.

Inductively Coupled Plasma Atomic Emission Spectroscopy (ICP-AES). We digested dried pellets of NCs in $0.2 \mathrm{~mL}$ of concentrated ultrapure nitric acid. The digested samples were then diluted to $10 \mathrm{~mL}$ with ultrapure water and passed through $0.2-\mu \mathrm{m}$ cellulose acetate syringe filters before the concentrations of $\mathrm{Cu}$ and $\mathrm{Cd}$ were measured on a Perkin-Elmer 8300 inductively coupled plasma atomic emission spectrometer. We generated calibration curves for the $\mathrm{Cu}$ and $\mathrm{Cd}$ atomic emission peaks using a series of solutions with known $\mathrm{Cu}$ and $\mathrm{Cd}$ concentrations prepared by diluting purchased standards $(1000 \mathrm{mg} / \mathrm{L}$, High Purity Standards). 


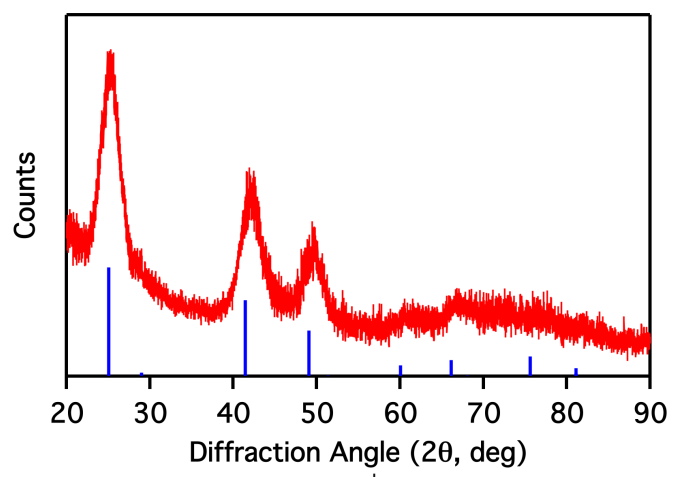

Figure S1. Powder X-ray diffraction of $\mathrm{Cu}^{+}$:CdSe NCs showing a zinc-blende lattice structure. Powder X-ray diffraction from films of $\mathrm{Cu}^{+}: \mathrm{CdSe} \mathrm{NCs}$ dropcast onto silicon substrate (red). Blue lines correspond to the zinc blende crystal structure of the bulk CdSe.
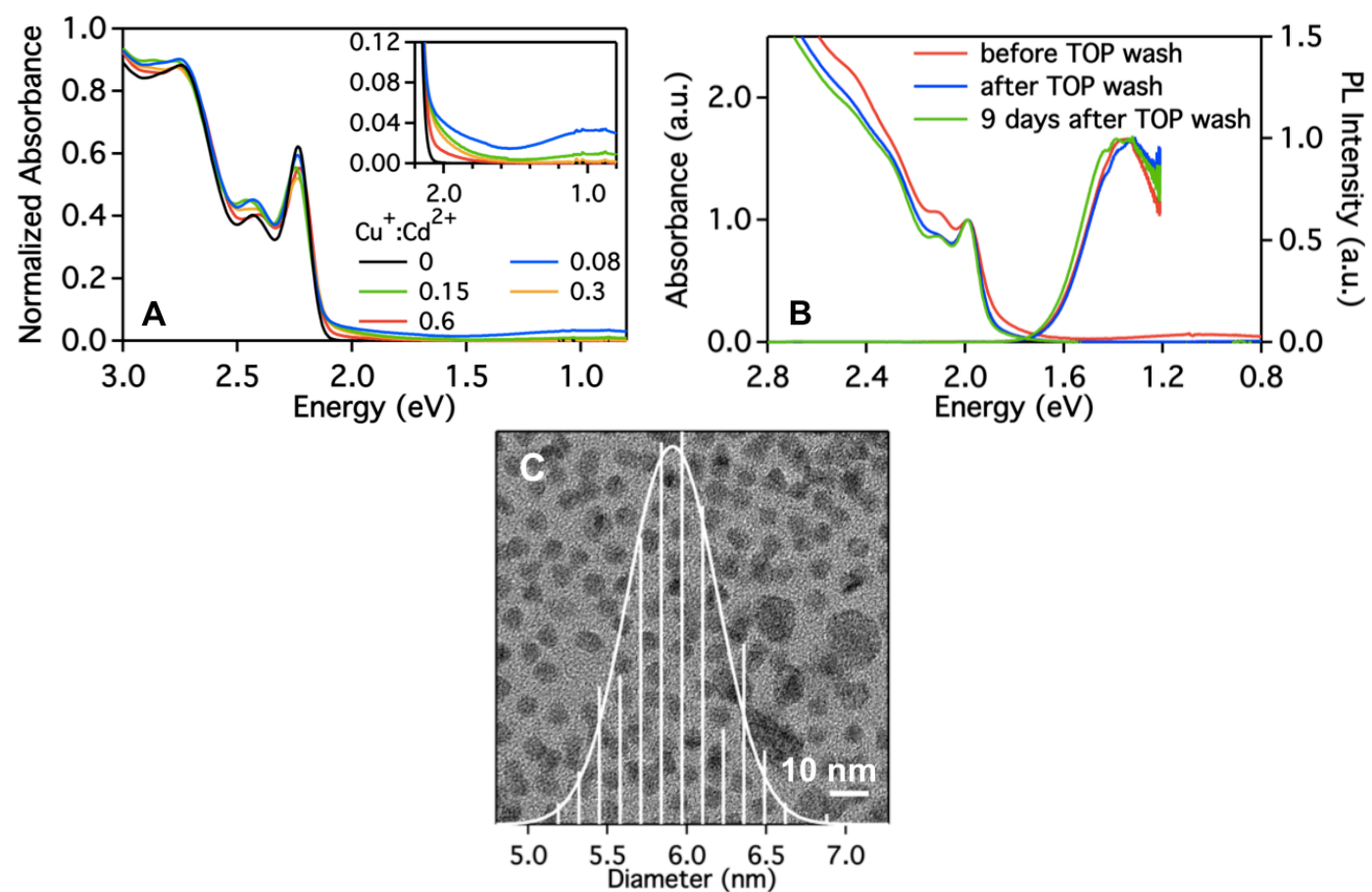

Figure S2. $\mathrm{Cu}_{2-\mathrm{x}} \mathrm{Se}$ impurities in as-synthesized $\mathrm{Cu}^{+}$:CdSe NCs can be removed through centrifugation or by addition of TOP at room temperature. (A) Electronic absorption spectra (normalized to $405 \mathrm{~nm}$ ) of toluene suspensions of the pellets acquired by precipitating the reaction mixture from the $\mathrm{Cu}^{+}: \mathrm{CdSe} \mathrm{NC}$ synthesis with ethanol/acetone and acetone following the standard synthetic procedure without centrifugation. The NCs are the same batches as are described in Figure 3 in the main text, which were synthesized under similar reaction conditions with varying molar ratios of $\mathrm{CuI}$ to cadmium oleate: $\mathrm{Cu}: \mathrm{Cd}=0$ (undoped, black), 0.075 (blue), 0.15 (green), 0.3 (orange), and 0.6 (red). (B) Electronic absorption and photoluminescence spectra of toluene solutions of as-synthesized $\mathrm{Cu}^{+}: \mathrm{CdSe} \mathrm{NCs}$ (red), the same NCs after addition of small amount of TOP under nitrogen atmosphere and subsequent purification by precipitation with ethanol-methanol mixture and centrifugation (blue), and the same NCs after 9 days after TOP treatment (green). (C) TEM images and corresponding diameter histogram of $\mathrm{Cu}^{+}:$CdSe NCs described in (B). The large NCs with $d>10 \mathrm{~nm}$ correspond to $\mathrm{Cu}_{2-\mathrm{x}} \mathrm{Se} \mathrm{NCs}$. The sample described in (B), after TOP washing, is the same as the sample described by the black trace in Figure 2A and the TEM in Figure 2E of the main text. 


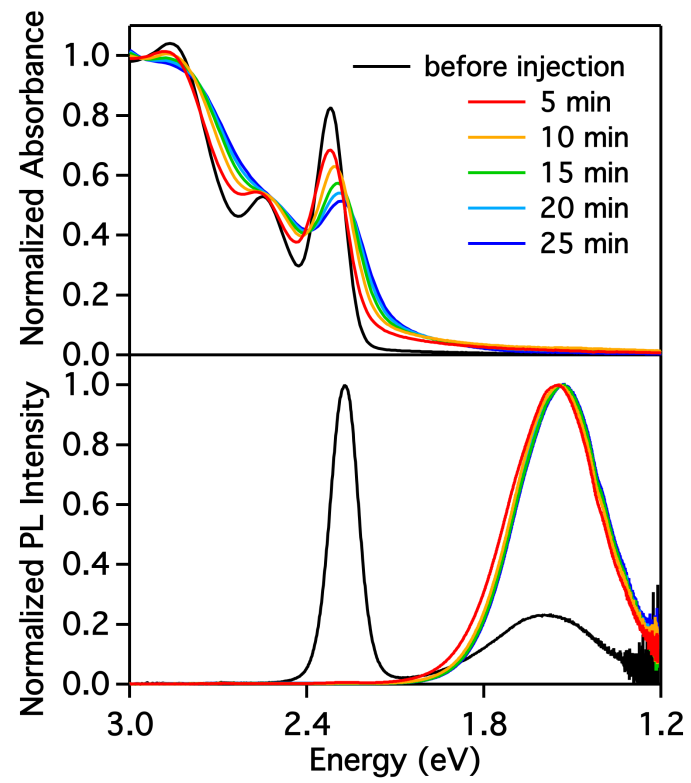

Figure S3. The formation of $\mathrm{Cu}_{2-x} \mathrm{Se}$ NCs is suppressed throughout the reaction under the optimized condition for $\mathrm{Cu}^{+}: \mathbf{C d S e} \mathrm{NC}$ synthesis. Temporal evolution of electronic absorption (top, normalized to $405 \mathrm{~nm}$ ) and photoluminescence (bottom, normalized to copper or exciton PL maxima for $\mathrm{Cu}^{+}: \mathrm{CdSe}$ or undoped $\mathrm{CdSe}$ ) spectra of toluene solution of aliquots removed prior to injection of copper precursor (black) and 5 min (red), $10 \mathrm{~min}$ (orange), $15 \mathrm{~min}$ (green), $20 \mathrm{~min}$ (cyan), and $25 \mathrm{~min}$ (blue) after injection from standard $\mathrm{Cu}^{+}: \mathrm{CdSe}$ synthesis. All aliquots are washed before taking spectra.

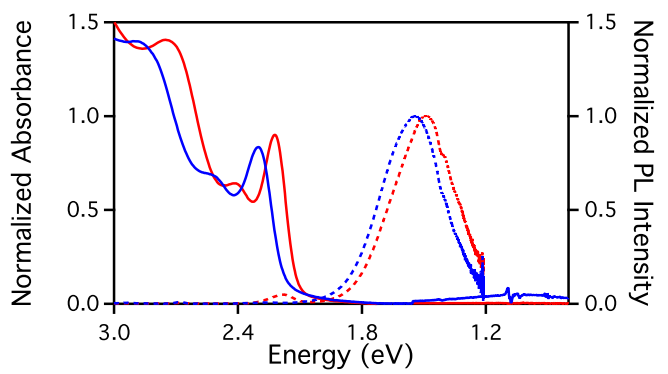

Figure S4. Synthesis of $\mathrm{Cu}^{+}$:CdSe NCs is successful using purified CdSe NCs as the starting material. Electronic absorption (normalized to $405 \mathrm{~nm}$, solid lines) and photoluminescence (normalized to PL maxima, dashed lines) spectra of toluene solutions of the $\mathrm{Cu}^{+}: \mathrm{CdSe} \mathrm{NCs}$ synthesized with the standard synthetic method (red) and the $\mathrm{Cu}^{+}: \mathrm{CdSe}$ NCs synthesized with purified CdSe NCs (blue). The latter synthesis is done by injecting $\mathrm{CuI}-\mathrm{ODE}$ into purified CdSe NCs at $235^{\circ} \mathrm{C}$ under nitrogen atmosphere in the absence of both selenium precursor and TOP, as is described in the SI Experimental Methods. 


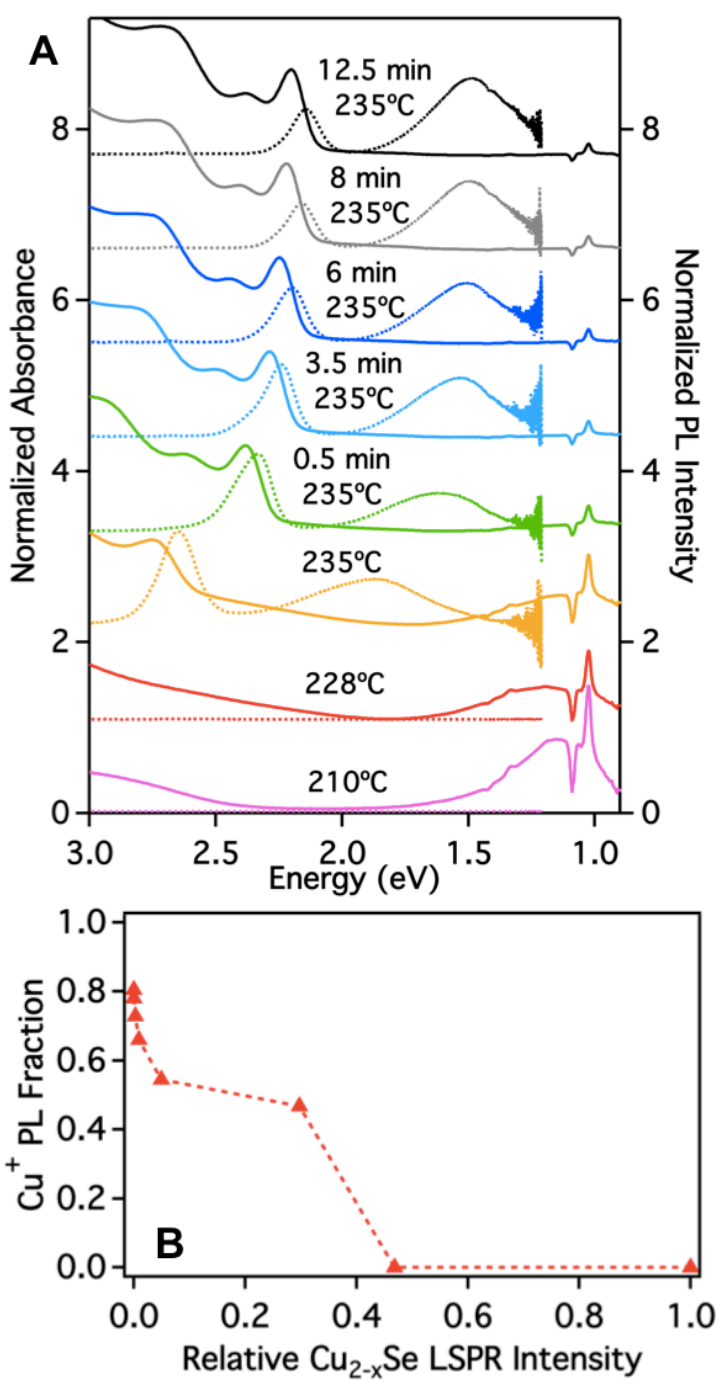

Figure S5. Conversion of $\mathrm{Cu}_{2-\mathrm{x}} \mathrm{Se} \mathrm{NC}$ to $\mathrm{Cu}^{+}: \mathrm{CdSe} \mathrm{NC}$ is observed in a reaction where $\mathrm{Cu}_{2-\mathrm{x}} \mathrm{Se} \mathrm{NCs}$ is the only copper precursor present in the reaction mixture. (A) Temporal evolution of electronic absorption (solid line, normalized to first exciton maxima) and photoluminescence (dotted line, normalized to total integrated PL intensity) spectra of toluene solutions of aliquots removed at $210{ }^{\circ} \mathrm{C}$ (pink), $228{ }^{\circ} \mathrm{C}$ (red), $235^{\circ} \mathrm{C}$ (orange), and 0.5 min (green), $3.5 \mathrm{~min}$ (cyan), $6 \mathrm{~min}$ (blue), $8 \mathrm{~min}$ (grey), and $12.5 \mathrm{~min}$ (black) after reaching $235^{\circ} \mathrm{C}$ from a one-pot heat-up synthesis of $\mathrm{Cu}^{+}: \mathrm{CdSe} \mathrm{NCs}$ using $\mathrm{Cu}_{2-\mathrm{x}} \mathrm{Se} \mathrm{NCs}$ as the copper precursor. (B) Plot of the fraction of the total integrated intensity from the $\mathrm{ML}_{\mathrm{CB}} \mathrm{CT}$ recombination of the $\mathrm{Cu}^{+}: \mathrm{CdSe} \mathrm{NCs}$ versus the relative intensity of the $\mathrm{Cu}_{2-\mathrm{x}} \mathrm{Se}$ LSPR at 1.2 $\mathrm{eV}$ for the aliquots described in $(\mathrm{A})$. 


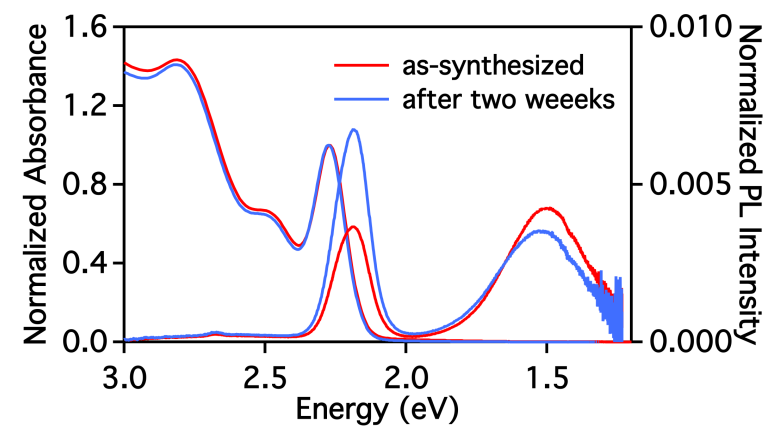

Figure S6. NCs synthesized in the presence of hexadecylamine experience decrease of copper-based PL and recovery of excitonic PL upon storage at room temperature in ambient atmosphere after purification. Electronic absorption (normalized to first excitonic maxima) and photoluminescence (normalized to total integrated intensity) spectra of toluene solutions of the as-synthesized $\mathrm{Cu}^{+}: \mathrm{CdSe} \mathrm{NCs}$ (red) and the same batch of NCs after storage at room temperature in ambient atmosphere for two weeks. The $\mathrm{Cu}^{+}: \mathrm{CdSe} \mathrm{NCs}$ are synthesized in an initial experiment where hexadecylamine is used in lieu of trioctylphosphine in the synthesis.

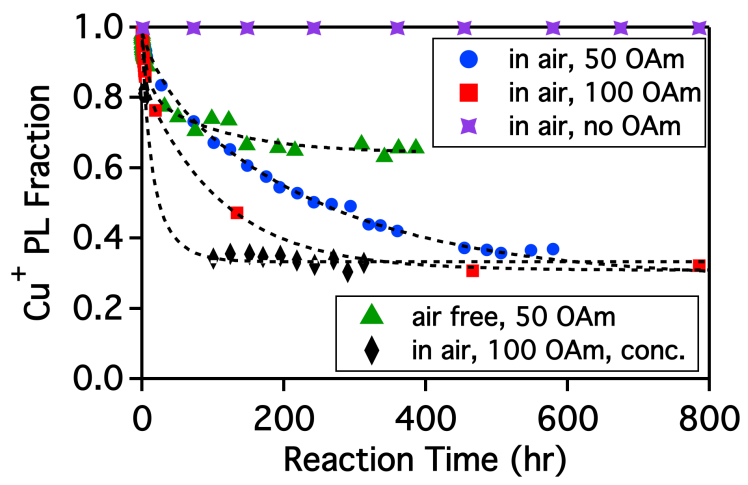

Figure S7. Kinetics of loss of copper upon addition of soft-base ligands to $\mathrm{Cu}^{+}$: $\mathrm{CdSe}$ NCs on a long timescale. Plot of the fraction of total integrated PL intensity from the nearIR region of $\mathrm{Cu}^{+}: \mathrm{CdSe} \mathrm{NCs}$ versus time upon addition of $\sim 50$ OAm per surface cation in ambient atmosphere (blue circles), 100 OAm per surface cation in ambient atmosphere (red squares and green triangles), $\sim 100 \mathrm{OAm}$ per surface cation under $\mathrm{N}_{2}$ atmosphere (black diamonds), and upon no addition of OAm (purple stars). The $\mathrm{Cu}^{+}: \mathrm{CdSe}$ concentration in reaction mixtures represented by blue, red, and green data points is $0.7 \mu \mathrm{M}$, and the concentration in that of the black data points is $0.1 \mathrm{mM}$. This plot comprises the complete data set of the experiments described in Figure $7 \mathrm{C}$ in the main text. The dashed black lines represent double exponential fits of the data. 

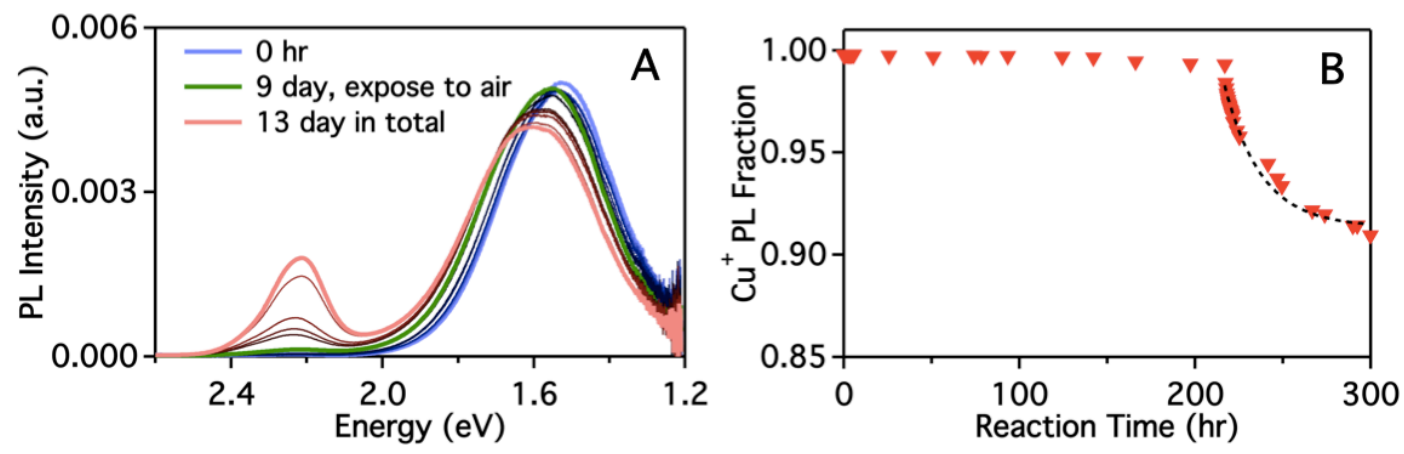

Figure S8. Addition of TOP under nitrogen atmosphere at room temperature results in no significant change in the PL spectra of $\mathrm{Cu}^{+}: \mathrm{CdSe} \mathrm{NCs}$, but recovery of excitonic emission is observed upon exposure to air. (A) Temporal evolution of the photoluminescence spectra (initial to final is light blue to light red) of $\mathrm{Cu}^{+}: \mathrm{CdSe}$ upon addition of 2500 TOP per surface cation to a $0.7 \mu \mathrm{M}$ toluene solution of $\mathrm{Cu}^{+}: \mathrm{CdSe}$ under nitrogen atmosphere. The green spectrum represents the reaction mixture immediately upon exposure to air 9 days after addition of TOP. (B) Plot of the fraction of the total integrated intensity from the copper PL of the reaction mixture described in (A) versus reaction time. The sudden decrease in the fraction of the copper PL intensity at 216 hours corresponds to exposure of the reaction mixture to air.
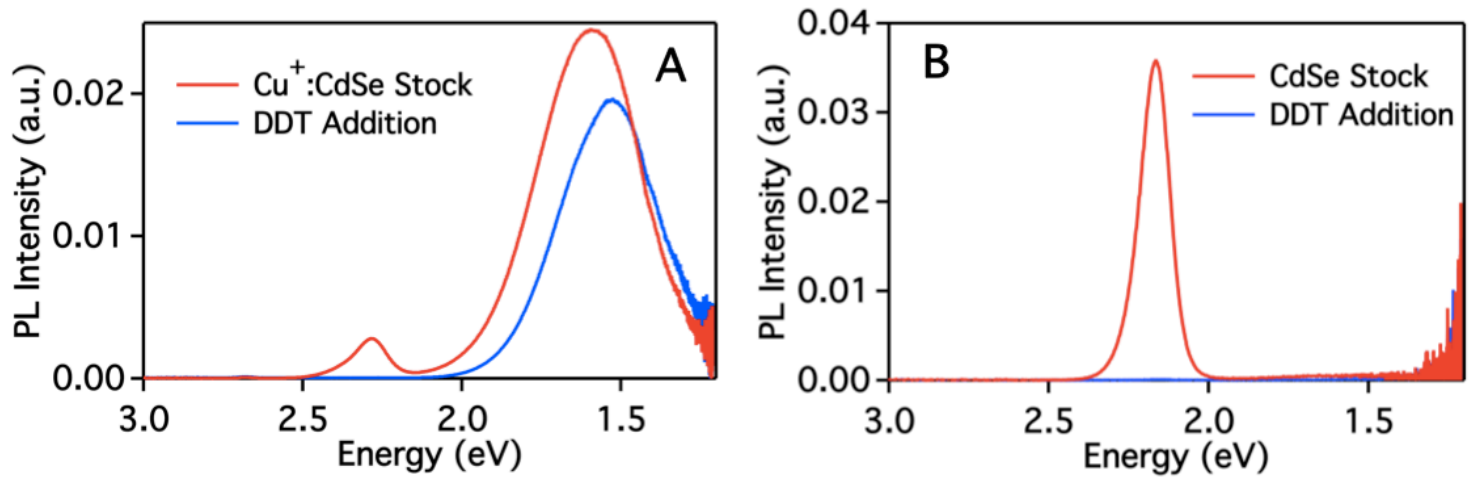

Figure S9. Increase of the relative intensity of the $\mathrm{ML}_{\mathrm{CB}} \mathrm{CT} \mathrm{PL}$ of $\mathrm{Cu}^{+}: \mathrm{CdSe}$ NCs upon addition of dodecanethiol (DDT) is due to preferential quenching of the excitonic PL in the undoped CdSe NC subset. PL spectra of toluene solutions of (A) as-synthesized $\mathrm{Cu}^{+}: \mathrm{CdSe}$ NCs containing a small subset of undoped CdSe NCs (red) and the same NCs immediately after addition of 500 dodecanethiol per surface cation (blue), (B) as-synthesized CdSe NCs (red) and the same NCs immediately after addition of 1000 dodecanethiol per surface cation (blue). Both $\mathrm{Cu}^{+}: \mathrm{CdSe}$ and $\mathrm{CdSe} \mathrm{NC}$ solutions have $\mathrm{NC}$ concentrations of $\sim 2$ $\mu \mathrm{M}$. 

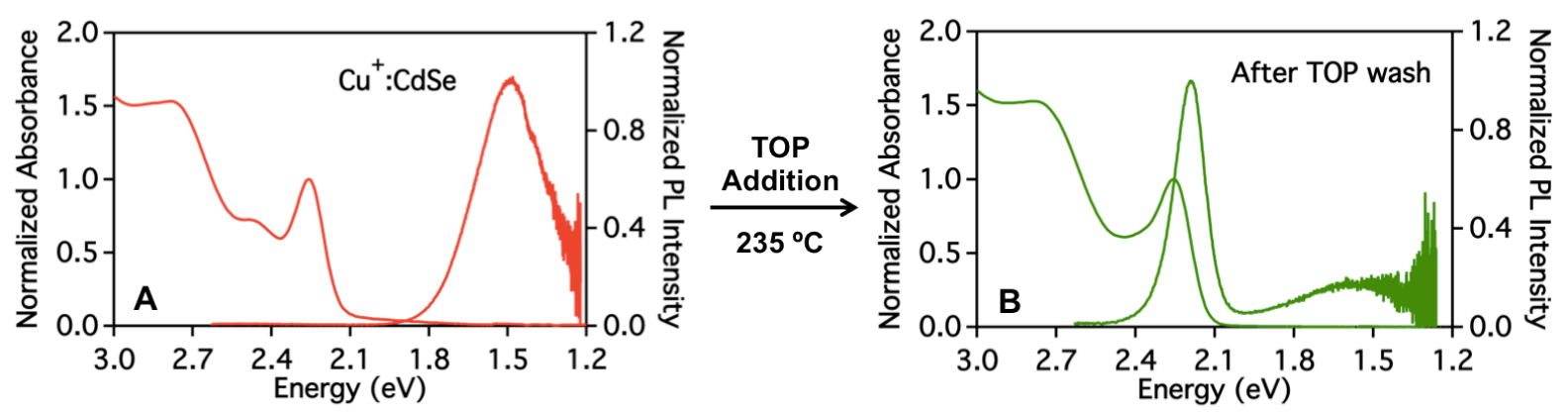

CdSe NCs

$\mathrm{Cu}^{+}$Cation Mole

Fraction: $0.8 \%$

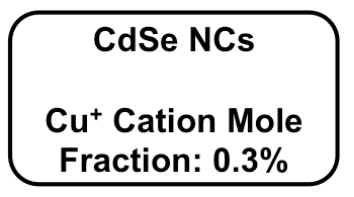

Figure S10. Removal of copper from $\mathrm{Cu}^{+}: \mathrm{CdSe} \mathrm{NCs}$ is observed upon addition of TOP at $235{ }^{\circ} \mathrm{C}$ under nitrogen atmosphere, as confirmed by the change in PL spectra and ICP-AES. Electronic absorption and photoluminescence spectra of toluene solutions of assynthesized $\mathrm{Cu}^{+}: \mathrm{CdSe} \mathrm{NCs}$ and the same NCs after post-synthesis ligand exchange treatment with TOP at $235{ }^{\circ} \mathrm{C}$ in nitrogen atmosphere. (A) As-synthesized $\mathrm{Cu}^{+}: \mathrm{CdSe} \mathrm{NCs}$ (B) $\mathrm{NCs}$ after addition of TOP and subsequent purification by precipitation with ethanol-methanol mixture and centrifugation. ICP measurements show that $\mathrm{Cu}^{+}: \mathrm{Cd}^{2+}$ ratio decreases from 0.008 in (A) to 0.003 in (B) after TOP treatment at $235^{\circ} \mathrm{C}$.

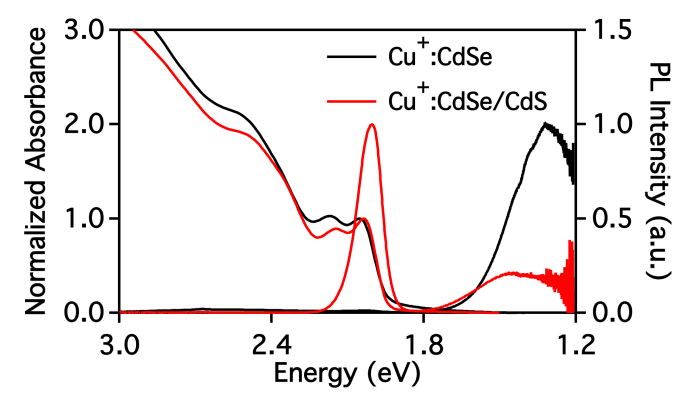

Figure S11. Loss of copper dopants is observed in an attempt to grow CdS shell on $\mathrm{Cu}^{+}:$CdSe NCs. Electronic absorption and photoluminescence spectra of toluene solution of $\mathrm{Cu}^{+}: \mathrm{CdSe} \mathrm{NCs}$ (black) and $\mathrm{Cu}^{+}: \mathrm{CdSe} / \mathrm{CdS}$ core/shell NCs (red). 


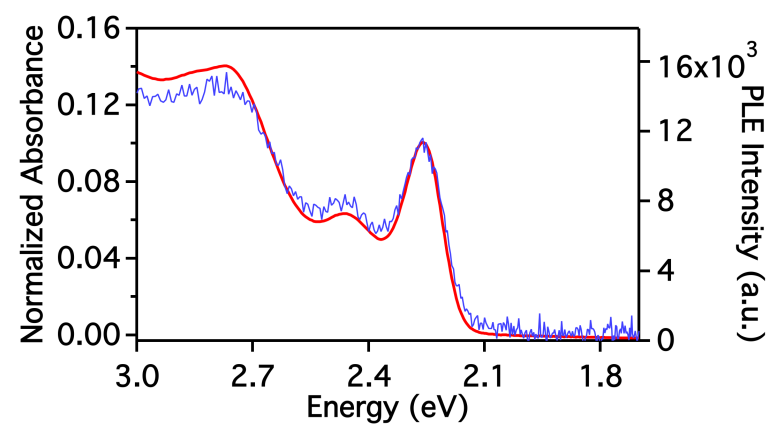

Figure S12. The PLE spectra of the $\mathrm{Cu}^{+}: \mathrm{CdSe}$ NCs are essentially superimposable with the electronic absorption spectra near the optical bandgap. PLE spectra of toluene solutions of $\mathrm{Cu}^{+}: \mathrm{CdSe} \mathrm{NCs}$ monitored at $\sim 1.6 \mathrm{eV}(780 \mathrm{~nm})$ and with excitation scanning from 3.00 to $1.70 \mathrm{eV}(415-730 \mathrm{~nm})$. The $\mathrm{Cu}^{+}: \mathrm{Cd}^{2+}$ ratios of the $\mathrm{Cu}^{+}: \mathrm{CdSe} \mathrm{NCs}$ measured by ICP-AES is 0.002 .

For the data in Figures 3 and 4 of the main text, the $\mathrm{ML}_{\mathrm{CB}} \mathrm{CT}$ extinction coefficient was quantified. The per- $\mathrm{Cd}^{2+}$ extinction coefficient at the $\mathrm{ML}_{\mathrm{CB}} \mathrm{CT}$ absorption maximum $\left(\varepsilon^{\prime} \mathrm{ML}_{\mathrm{CB}} \mathrm{CT}\right)$ is defined by eq $\mathrm{S} 1$ in terms of the absorbance at the $\mathrm{ML}_{\mathrm{CB}} \mathrm{CT}$ peak maximum $\left(A_{\mathrm{ML}_{\mathrm{CB}} \mathrm{CT}}\right.$, determined by Gaussian fitting), the concentration of $\mathrm{Cd}^{2+}$ ions (= concentration of CdSe units in the NC), and the cell pathlength $(\ell)$, according to the Beer-Lambert law. Using the known size-independent per-Cd ${ }^{2+}$ extinction coefficient, $\varepsilon_{\mathrm{Cd}, 340} \approx 2060 \mathrm{M}_{\mathrm{Cd}}{ }^{-1} \mathrm{~cm}^{-1}$ for zinc blende CdSe at $340 \mathrm{~nm},{ }^{18}$ we can determine $\varepsilon_{\mathrm{ML}_{\mathrm{CB}} \mathrm{CT}}$ experimentally using the measured absorbance at $340 \mathrm{~nm}\left(A_{340}\right)$.

$$
\varepsilon_{\mathrm{ML}_{\mathrm{CB}} \mathrm{CT}}^{\prime} \stackrel{\text { def }}{=} \frac{A_{\mathrm{ML}_{\mathrm{CB}} \mathrm{CT}}}{[\mathrm{Cd}] \ell}=\frac{A_{\mathrm{ML}_{\mathrm{CB}} \mathrm{CT}}}{A_{340}} \varepsilon_{\mathrm{CdSe}, 340}
$$

We note that this analysis relies on the assumption that the $\mathrm{Cu}^{+}$dopants do not introduce significant absorption at $340 \mathrm{~nm}$, which is reasonable given their small concentration.

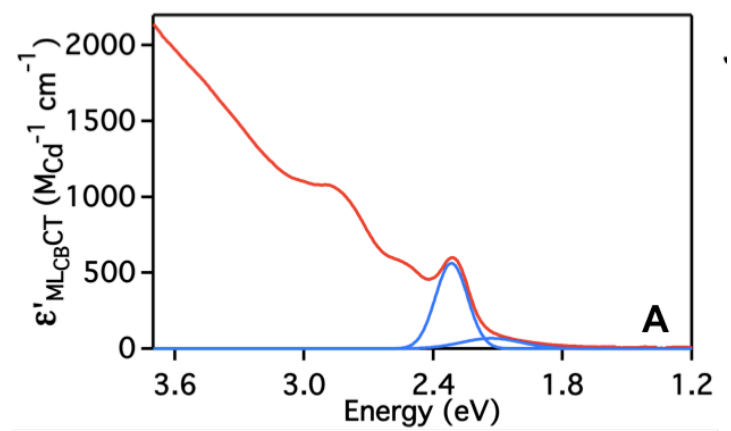

Figure S13. Gaussian resolution of $\mathrm{ML}_{\mathrm{CB}} \mathrm{CT}$ absorption band. Example of a Gaussian fit of the $\mathrm{ML}_{\mathrm{CB}} \mathrm{CT}$ absorption used to quantify the $\mathrm{ML}_{\mathrm{CB}} \mathrm{CT}$ absorbance values plotted in Fig. 3 of the main text, and used for Fig. 4 of the main text. The $y$ axis is plotted as $\varepsilon^{\prime}{ }_{\mathrm{ML}_{\mathrm{CB}} \mathrm{CT}}$, which is defined by eq $\mathrm{S} 1$. 


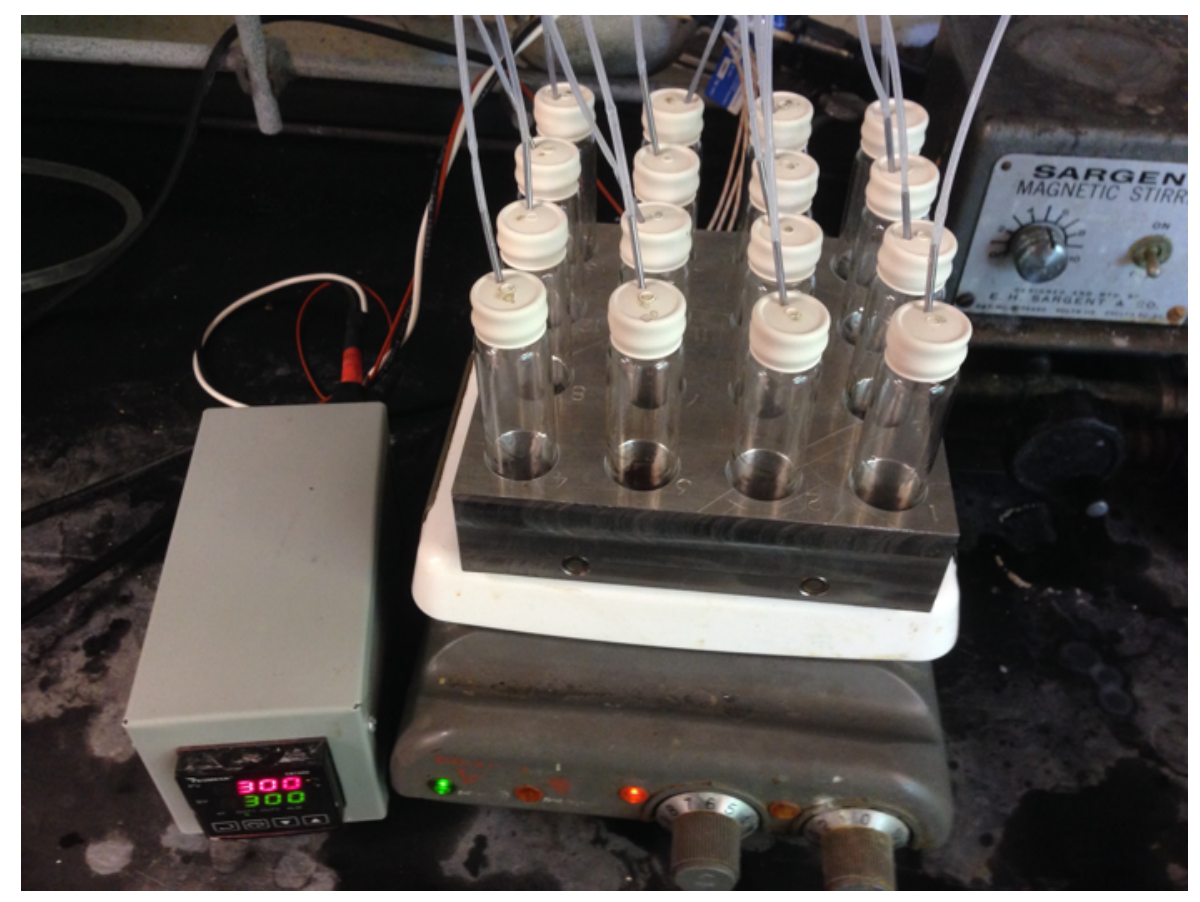

Figure S14. Custom-built 16-well reactor used to conduct multiple reactions in parallel. The aluminum block connects to a temperature controller and sits on a stir plate, such that all reactions can be heated and stirred simultaneously. Reaction vials can then be connected to a nitrogen source. Photograph courtesy of Charles Barrows.

\section{References}

(1) Kriegel, I.; Jiang, C. Y.; Rodriguez-Fernandez, J.; Schaller, R. D.; Talapin, D. V.; da Como, E.; Feldmann, J., Tuning the Excitonic and Plasmonic Properties of Copper Chalcogenide Nanocrystals. J. Am. Chem. Soc. 2012, 134, 1583-1590. 